\title{
Synthesis and Investigation of Antimicrobial Activity of Tin Oxide Nanoparticles by Microwave Assisted Solution Method
}

\author{
S. Rajeswari1, J. Uma Maheswari1, D. Muthuraj1,*, E. Kumar², V. Veeraputhiran ${ }^{3}$ \\ ${ }^{1} P G$ and Research Department of Physics, The M.D.T. Hindu College, Tirunelveli - 627 010, Tamilnadu, India. \\ ${ }^{2}$ Department of Physics, School of Science, Tamil Nadu Open University, Chennai - 600 015, Tamilnadu, India. \\ ${ }^{3} R$ \& D Department, Alba Industries Pvt. Ltd., Thoothukudi - 628 103, Tamilnadu, India.
}

\section{ART I C LE DETAILS}

\section{Article history:}

Received 05 March 2019

Accepted 27 March 2019

Available online 31 March 2019

\section{A B S T R A C T}

Tin oxide $\left(\mathrm{SnO}_{2}\right)$ nanoparticles have been synthesized via microwave-assisted solution method. The structural analysis was carried out using X-ray diffraction. It showed that the $\mathrm{SnO}_{2}$ nanoparticle exhibited primitive tetragonal structure. The $\mathrm{SnO}_{2}$ product was investigated by FT-IR, UV, SEM and antimicrobial activity studies of $\mathrm{SnO}_{2}$ have confirmed that they have biomedical applications.

\section{Keywords:}

Tin Oxide

Microwave Method

Antimicrobial Activity

\section{Introduction}

Nanotechnology is the most essential and electrifying forefront field in physics, chemistry, engineering and biology. In semiconductor nanoparticles, the particle size influences the optical, catalytic, electric and magnetic properties [1]. Tin oxide $\left(\mathrm{SnO}_{2}\right)$ is an $n$ type semiconductor with direct band gap, transparent and sensitive to gases [2-4]. $\mathrm{SnO}_{2}$ nanoparticles used in gas sensors, solar cells, transistors, etc. Many processes have been developed to the synthesis of $\mathrm{SnO}_{2}$ nanostructures includes spray pyrolysis, hydrothermal methods, chemical vapor deposition, thermal evaporation of oxide powders and sol-gel method [510]. In the present work the synthesis and characterization of antimicrobial activity of $\mathrm{SnO}_{2}$ nanoparticles powder by microwaveassisted solution method was studied.

\section{Experimental Methods}

\subsection{Materials}

All the chemicals were used as analytical grade without any further purification. Stannous chloride dihydrate and ammonia were used to prepare the nanoparticles of this work. Double distilled deionized water used in this investigation. Disc diffusion method has employed with Escherichia coli and Staphylococcus aureus.

\subsection{Synthesis}

Initially, in a typical synthesis of synthesis of $\mathrm{SnO}_{2}$ nanoparticles, $3 \mathrm{~g}$ of stannous chloride dihydrate $\left[\mathrm{SnCl}_{2} .2 \mathrm{H}_{2} \mathrm{O}\right]$ was completely dissolved in 50 $\mathrm{mL}$ deionized water. Then $50 \mathrm{~mL}$ ammonia solution was added drop by drop in the solution with constant stirring at $70{ }^{\circ} \mathrm{C}$ and its $\mathrm{pH}$ value of the mixture was maintained at 12 . The stirring was continued for 1 hour. Then the prepared mixture solution was kept in the microwave oven $(900 \mathrm{~W}$, $2450 \mathrm{MHz}$ Onida, India) at a temperature of $70{ }^{\circ} \mathrm{C}$ for about 20 minutes. Finally, the as prepared sample was centrifuged and washed several times in double distilled water to remove the by-product, and dried in room temperature for 24 hours results in the formation of $\mathrm{SnO}_{2}$ nanoparticles. 
peaks of the XRD pattern, the particle size is estimated and the average size of nanoparticles of the sample is found to be around $16-20 \mathrm{~nm}$.

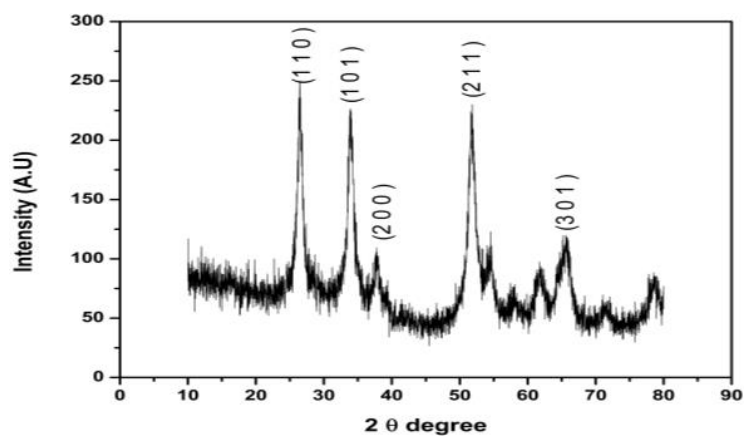

Fig. 1 XRD pattern $\mathrm{SnO}_{2}$ nanoparticles

\subsection{FT-IR Method}

The infrared spectroscopy is effectively used to identify the functional groups of the synthesized compounds. The FT-IR spectrum of as-prepared $\mathrm{SnO}_{2}$ nanoparticles is shown in the Fig. 2 .

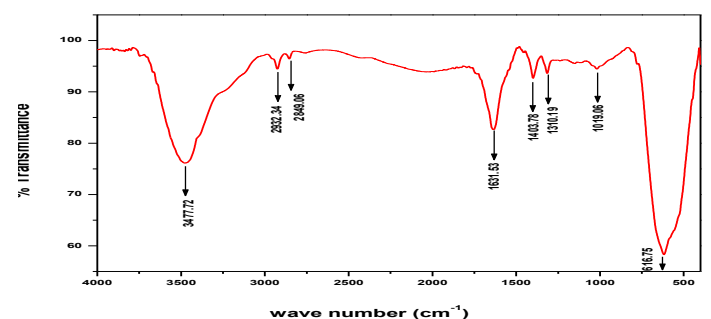

Fig. 2 FT-IR spectrum of $\mathrm{ZrO}_{2}$ nanoparticles

The band at $3477 \mathrm{~cm}^{-1}$ is appeared due to $\mathrm{OH}$ stretching vibrations of free and hydrogen-bonded hydroxyl groups [13]. The narrow peak at 616 $\mathrm{cm}^{-1}$ confirms the formation of crystalline $0-\mathrm{Sn}-0$ mode of the tin oxide [16]. It confirms the presence of $\mathrm{SnO}_{2}$ as crystalline phase. This is in a good agreement with the results of the XRD analysis. The peak at $1631 \mathrm{~cm}^{-1}$ may be due to the adsorbed water and ammonia [14]. The intense and broad bands at $3433 \mathrm{~cm}^{-1}$ and $1638 \mathrm{~cm}^{-1}$ can be attributed to the $\mathrm{O}-\mathrm{H}$ vibration in absorbed water on the sample surface [15]. The broad bands between 450 and $790 \mathrm{~cm}^{-1}$ are attributed to the framework vibrations of the $\mathrm{Sn}-0$ bond in $\mathrm{SnO}_{2}$ [16]. It can be seen that, the absorption spectrum is dominated with very strong and broad absorption peak spread over the spectral region (3600-3000 $\left.\mathrm{cm}^{-1}\right)$. This effect is thought to be due to adsorbed water vapor since these features are consistent with underlying (H-bonded) $\mathrm{OH}$ stretching bands. However, one can see weak shoulders riding over this broad peak. The aromatic $\mathrm{C} \mathrm{H}$ stretching vibration is easily identifiable above $3000 \mathrm{~cm}^{-1}$ as a weak peak at $3141 \mathrm{~cm}^{-1}$. The absorption band appeared at $3201 \mathrm{~cm}^{-1}$ and a shoulder at approximately $3439 \mathrm{~cm}^{-1}$ are assigned to hydrogen bonded symmetric and asymmetric $\mathrm{N}-\mathrm{H}$ stretching vibrations.

\section{$3.3 \mathrm{UV}$-Vis Analysis}

UV-Visible absorption spectral study may be assisted in understanding electronic structure of the optical band gap of the material. The room temperature ultraviolet-visible spectra of $\mathrm{SnO}_{2}$ nanoparticles samples were recorded using UV-1800 series spectrophotometer in the absorption mode. The UV-absorption edge provides a reliable estimate of the band gap of any system. The optical absorption spectra of the $\mathrm{SnO}_{2}$ nanoparticles are presented in Fig. 3. The absorption band edge is observed at $295 \mathrm{~nm}$, which clearly indicates a blue shift from the bulk $\mathrm{SnO}_{2}$ $(340 \mathrm{~nm})$ [17]

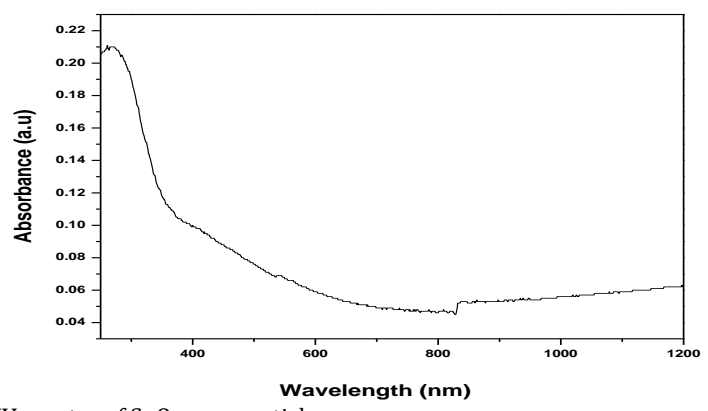

Fig. 3 UV spectra of $\mathrm{SnO}_{2}$ nanoparticles

https://doi.org/10.30799/jnst.214.19050115

\subsection{SEM and HRTEM Analysis}

The morphology and size of nanoparticles are analysed using a scanning electron microscope (SEM). The SEM images of as-prepared tin oxide are shown in Fig. 4. Also it is observed that the most of the particles of the samples are spherical shape of tin oxide with some agglomeration of finer particulates to form bigger clusters. The particles are fine and granular in nature and seemed to be nanosized, typically in the range of $<$ $30 \mathrm{~nm}$.

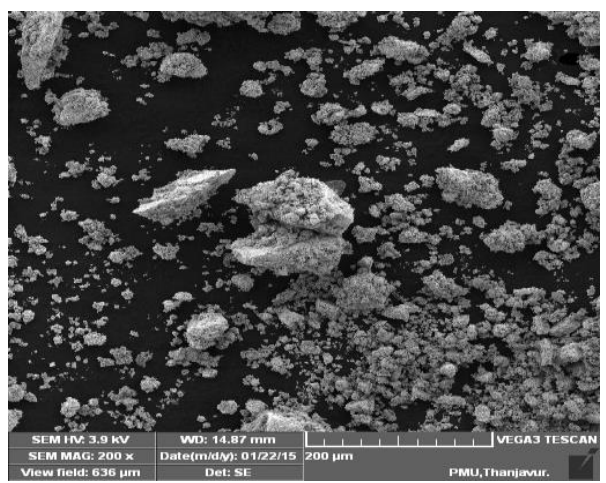

Fig. 4 SEM image of $\mathrm{SnO}_{2}$ nanoparticles

The HRTEM images of as-prepared $\mathrm{SnO}_{2}$ and are presented in Fig. 5 . Also, it is observed that the shapes of most of the particles are nearly spherical and can be arranged in different ways. To obtain a particle size distribution from transmission electron micrographs we manually measured the particle sizes for 10 particles to ensure a reliable representation of the actual size distribution. The crystallite size is about 5-20 nm as estimated from the TEM micrographs. The experimental and calculated XRD patterns provide a volume-weighted average grain size of $16 \mathrm{~nm}$, which is in good agreement with the particle size observable on the TEM image. The interplanar spacing of the $\mathrm{SnO}_{2}$ nanoparticles is about $0.33 \mathrm{~nm}$, which is identical with the $\left(\begin{array}{lll}1 & 1 & 0\end{array}\right)$ facet distance of bulk $\mathrm{SnO}_{2}$ phase. From SEM and HRTEM images, the morphology of nanoparticles is observed to be spherical shaped particles with slight agglomeration.

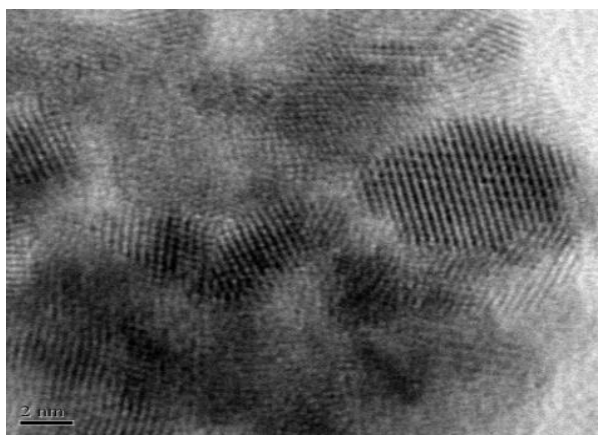

Fig. 5 HRTEM image of $\mathrm{SnO}_{2}$ nanoparticles

\subsection{Antimicrobial Activity}

The antimicrobial activity of $\mathrm{SnO}_{2}$ was investigated against gramnegative bacteria (Escherichia coli) and gram-positive bacteria (Staphylococcus aureus), respectively. The prepared $\mathrm{SnO}_{2}$ nanoparticles showed a good inhibitory action against Escherichia coli (inhibition zone size of $22 \mathrm{~mm}$ ) at the $100 \mu \mathrm{g} / \mathrm{mL}$ compared to other bacteria due to the negatively charged, Staphylococcus aureus (inhibition zone size of $18 \mathrm{~mm}$ ) cell wall readily attracting positively charged $\mathrm{SnO}_{2}$, and in that way inhibiting microbial actions. In addition, the $\mathrm{SnO}_{2}$ nanoparticle was directly proportional to their inhibitory actions beside the tested microorganism. Finally, confirmed prepared $\mathrm{SnO}_{2}$ nanoparticles are more stable and have antimicrobial activity behavior.

\section{Conclusion}

$\mathrm{SnO}_{2}$ nanoparticles powder was synthesized at $70{ }^{\circ} \mathrm{C}$ by microwaveassisted solution method. The XRD pattern exhibited peaks for nanocrystalline $\mathrm{SnO}_{2}$ are observed and indexed to $\left(\begin{array}{lll}1 & 1 & 0\end{array}\right),\left(\begin{array}{lll}1 & 0 & 1\end{array}\right),\left(\begin{array}{lll}2 & 0 & 0\end{array}\right)$, (2 11 1), ( $\left.\begin{array}{lll}3 & 1 & 0\end{array}\right)$ and $\left(\begin{array}{lll}3 & 0 & 1\end{array}\right)$ having primitive tetragonal structure of $\mathrm{SnO}_{2}$. From SEM image, it is observed that the most of the agglomerated particles of the samples are spherical shape of tin oxide. FTIR broad bands between 450 and $790 \mathrm{~cm}^{-1}$ are attributed to the framework vibrations of the $\mathrm{Sn}-0$ bond in $\mathrm{SnO}_{2}$. At room temperature ultraviolet-visible spectrum of $\mathrm{SnO}_{2}$ 
nanoparticles were recorded using UV-1800 series spectrophotometer in the absorption mode and absorption band edge is observed at $295 \mathrm{~nm}$ with blue shift. A good antimicrobial activity of $\mathrm{SnO}_{2}$ was found against gram-negative bacterium Escherichia coli and gram-positive bacterium Staphylococcus aureus, respectively, and thus the synthesized $\mathrm{SnO}_{2}$ nanoparticles have confirmed that they have possible biomedical applications.

\section{References}

[1] L.C. Nehru, V. Swaminathan, C. Sanjeeviraja, Photoluminescence studies on nanocrystalline tin oxide powder for optoelectronic devices, Am. J. Mat. Sci. 2 (2012) 6-10.

[2] J. Zhu, J.M. Zhu, X.H. Liao, J.L. Fang, M.G. Zhou, H.Y. Chen, Rapid synthesis of nanocrystalline $\mathrm{SnO}_{2}$ powders by microwave heating method, Mater. Lett. 53(1-2) (2002) 12-19.

[3] T. Krishnakumar, Nicola Pinna, K. Prasanna Kumari, K. Perumal, R. Jeyaprakash, Microwave-assisted synthesis and characterization of tin oxide nanoparticles, Mater. Lett. 62(19) (2008) 3437-3440.

[4] Z. Li, W. Shen, X. Zhang, L. Fang, X. Zu, Controllable growth of $\mathrm{SnO}_{2}$ nanoparticles by citric acid assisted hydrothermal process, Colloid. Surf. A 327 (2008) 17-20.

[5] F. Paraguay-Delgado, W. Antúnez-Flores, M. Miki-Yoshida, A. AguilarElguezabal, P. Santiago, et al., Structural analysis and growing mechanisms for long $\mathrm{SnO}_{2}$ nanorods synthesized by spray pyrolysis, Nanotechnol. 16 (2005) 688-694.

[6] R. Mishra, P.K. Bajpai, Synthesis dielectric and electrical characterization of $\mathrm{SnO}_{2}$ nano-particle prepared by co-precipitation method, Jour. Int. Acad. Phy. Sci. 14 (2) (2010) 245-250.
[7] Z. Chen, J.K.L. Lai, C.H. Shek, Haydn Chen, Synthesis and structural characterization of rutile $\mathrm{SnO}_{2}$ nanocrystals, J. Mater. Res. 18(6) (2003) 12891292.

[8] M.M.B. Mohagheghia, N. Shahtahmasebia, M.R. Alinejada, A. Youssefic, M. Shokooh-Saremid, The effect of the post-annealing temperature on the nanostructure and energy band gap of $\mathrm{SnO}_{2}$ semiconducting oxide nano-particles synthesized by polymerizing-complexing sol-gel method, Physica B 403 (2008) 2431-2437.

[9] F. Du, Z. Guo, G. Li, Hydrothermal synthesis of $\mathrm{SnO}_{2}$ hollow microspheres, Mater. Lett. 59(19-20) (2005) 2563-2565.

[10] Y. Liu, E. Koep, M. Liu, A highly sensitive and fast-responding $\mathrm{SnO}_{2}$ sensor fabricated by combustion chemical vapor deposition, Chem. Mater. 17(15) (2005) 3997-4000.

[11] S. Li, H. Wang, W. Xu, H. Si, X. Tao, S. Lou, Z. Du, L.S. Li, Synthesis and assembly of monodisperse spherical $\mathrm{Cu}_{2} \mathrm{~S}$ nanocrystals, Colloid. Interf. Sci. 330(2) (2009) 483-487.

[12] S. Komarneni, R. Rajha, Microwave-hydrothermal processing of titanium dioxide, Mater. Chem. Phy. 61(1) (1999) 50-54.

[13] T. Krishnakumar, R. Jayaprakash, M. Parthibavarman, A.R. Phani, V.N. Singh, B.R. Mehta, Microwave-assisted synthesis and investigation of $\mathrm{SnO}_{2}$ nanoparticles, Mater. Lett. 63 (2009) 896-898.

[14] H.H. Son, W.G. Lee, Annealing effects for calcination of tin oxide powder prepared via homogeneous precipitation, J. Indus. Eng. Chem. 18 (2012) 317320.

[15] G.L. Zou, R. Liu, W.X. Chen, Z.D. Xu, Preparation and characterization of lamellar-like $\mathrm{Mg}(\mathrm{OH})_{2}$ nanostructures via natural oxidation of $\mathrm{Mg}$ metal in formamide/water mixture, Mater. Res. Bull.42 (2007) 1153-1158.

[16] J. Zhang and L. Gao, Synthesis and characterization of nanocrystalline tin oxide by sol-gel method, J. Solid State Chem. 177 (2004) 1425-1430.

[17] F. Gu, S.F. Wang, C.F. Song, M.K. Lu, Y.X. Qi, et al., Synthesis and luminescence properties of $\mathrm{SnO}_{2}$ nanoparticles, Chem. Phys. Lett. 372 (2003) 451-454. 